\title{
Complete Pharyngeal Contraction
}

National Cancer Institute

\section{Source}

National Cancer Institute. Complete Pharyngeal Contraction. NCI Thesaurus. Code C127315.

A finding of complete pharyngeal contraction during swallowing. 